This is the author's accepted manuscript version.

Cite: Li, Yingguang, Li, Nanya and Gao, James (2014) Tooling design and microwave curing technologies for the manufacturing of fiber-reinforced polymer composites in aerospace applications. The International Journal of Advanced Manufacturing Technology, 70 (1-4). pp. 591-606. ISSN 0268-3768 (Print), 1433-3015 (Online). doi:10.1007/s00170-013-5268-3

\title{
Tooling Design and Microwave Curing Technologies for the Manufacturing of Fiber-reinforced Polymer Composites in Aerospace Applications
}

\author{
Yingguang $\mathrm{Li}^{1}$, Nanya $\mathrm{Li}^{1}$, James $\mathrm{Gao}^{2}$
}

\begin{abstract}
The increasing demand for high performance and quality polymer composite materials has led to international research effort on pursuing advanced tooling design and new processing technologies to satisfy the highly specialised requirements of composite components used in the aerospace industry. This paper reports the problems in the fabrication of advanced composite materials identified through literature survey, and an investigation carried out by the authors about the composite manufacturing status in China's aerospace industry. Current tooling design technologies use tooling materials which cannot match the thermal expansion coefficient of composite parts, and hardly consider the calibration of tooling surface. Current autoclave curing technologies cannot ensure high accuracy of large composite materials because of the wide range of temperature gradients and long curing cycles. It has been identified that microwave curing has the potential to solve those problems. The proposed technologies for the manufacturing of fiber-reinforced polymer composite materials include the design of tooling using anisotropy composite materials with characteristics for compensating part deformation during forming process, and vacuum-pressure microwave curing technology. Those technologies are mainly for ensuring the high accuracy of anisotropic composite parts in aerospace applications with large size (both in length and thickness) and complex shapes. Experiments have been carried out in this on-going research project and the results have been verified with engineering applications in one of the project collaborating companies.
\end{abstract}

Key words polymer composites manufacturing, anisotropic composite tooling design, vacuum-pressure microwave curing, aerospace composite materials

\section{Introduction}

Fiber-reinforced polymer composite materials with high mechanical strength and fatigue resistance, light weight, and excellent high-temperature characteristics are the combination of

1 College of Mechanical and Electrical Engineering,

Nanjing University of Aeronautics and Astronautics, Nanjing, 210016, China.

Yingguang Li $(\bowtie)$ : liyingguang @ nuaa.edu.cn

2 Centre for Innovative Product Development \& Manufacturing, School of Engineering, University of Greenwich, Chatham Maritime, Kent, ME4 4TB, UK 
various polymer matrix and fibers. Owing to its excellent mechanical properties, fiber reinforced composites are the promising solutions to the various commercial applications [1-3], especially in the weight-critical aerospace industry. Aerospace applications pursuit best performance, and traditional materials cannot meet the highly specialized requirement, therefore, advanced composite materials with much better and controllable functional properties become widely used in aerospace structures [4]. Commercial aircrafts, military aircrafts, space aircrafts and helicopters, all make substantial use of composites, both for interior and exterior structures [5]. Polymer composite structures like wing-covers, aircraft leading edges and composite fuselages become the standard use in advanced aircrafts, which not only reduce structural weight, but also provide better stiffness, toughness, fatigue strength, energy absorption, and thermal stability than traditional materials [6,7]. Currently, composite materials represent $50 \%$ of the weight for Boeing 787 Dreamliners and $52 \%$ for Airbus 350XWB airplanes [8]. More fiber reinforced composites are being applied in their aircraft structures such as by the two giant aerospace companies. China's aerospace industry has advanced at an impressive rate over the past two decades. The data in Figure 1 shows major countries' aerospace manufacturing investments from 1990 - 2009 [9]. It can be seen that China has invested more than USA in the aerospace field over the past two decades (the vertical axis represents the numbers of investment projects). According to the data released at AVIC's 2009 company summit meeting [10], the total value of the company's subcontract deliveries in 2008 reached $\$ 639$ million, a 35\% year-on-year increase over 2007.

The investigation by AeroStrategy Management Consulting [9] shows that China is a popular location for manufacturing investments and has a broad aerospace supplier base to set up aerospace industry. This can dramatically promote the composite materials manufacturing business in aircraft components. Many domestic aircraft industries of China have already built their own composite design, processing and testing facilities. The development of advanced composite materials has become one of the new forces to drive China's aerospace industry. The proportion of composite structures used in aircrafts increased very quickly. For example, a series of main load-bearing and complex composite components have been used in China's domestic airplanes C919, nearly reaching $23 \%$, including composite wings, wing fuel tanks, center tanks, empennages and control surfaces [11]. 
The trend of the application of Advanced High Performance (AHP) composite components (including anisotropic composite materials) is for larger size (in length and thickness), higher dimensional and geometric accuracy and complex surfaces. The AHP composite materials, especially for anisotropic materials such as unsymmetrical composites, have attracted researchers' interest in developing morphing and shape control technologies in aerospace applications [12]. Higher component accuracy and quality can be achieved by designing the surfaces of tools and reducing tool-part interaction. Therefore, tooling design plays a major role in deformation control. Metal tooling has high coefficient of thermal expansion (CTE), high weight and difficult-to-cut characteristics, which makes it a new challenge in aerospace manufacturing. More tooling is being built using composite materials [13]. The CTE of Anisotropic Composite Tooling (ACT) may be designed to have almost the same CTE of AHP composite components in all directions. Recently, most AHP composite materials have been developed into thick components with variable cross-sections. This trend adds more problems to composite materials fabrication. Non-uniform temperature distribution and cracks often appear in composite parts during manufacturing using traditional techniques.

In order to improve the property of thick composite materials, especially for large-scale and high quality composite materials, this project investigated microwave curing technologies which have significantly shorter curing cycle and produce better performing composites with thick cross sections (e.g., 24.5mm), compared with conventional thermal curing technologies [14]. This research is carried out in response to the demand of the aircraft manufacture industry identified in a comprehensive investigation of composite structures used in the aerospace industry.

The purpose of this study is to develop new methods for composite tooling design, and more effective microwave curing technologies. The project will use anisotropic composite materials for tooling, and develop theoretical models to predict the expansion of tools during forming process to match the expansion of composite components, and to calibrate tool surfaces to compensate the deformation of components after the forming process. In microwave curing technology, this project will use electromagnetic to penetrate composite tooling and heat the thick non-symmetric composite materials with vacuum-pressure, and use distributed temperature control methods to optimize the temperature distribution across the external surfaces and throughout the entire volume of the material, so as to reduce non-uniform curing and thus obtain good quality. 


\section{An Industrial Investigation}

The aim of this investigation is to obtain an estimate of the trend at which large size, higher dimensional and geometric accuracy, complex surface and anisotropic composite materials have been used in aerospace field. A list of questionnaire-based surveys have been carried out in Chengdu Aircraft Industry Group Co. and Hongdu Aircraft Industry Group Co.. Their engineers in Composite Materials Processing Plant (CMPP) responded to the questionnaires. A total of 20 questionnaires have been answered by the two companies by telephone interviews. Over $90 \%$ respondents have more than 5 years' working experiences in aerospace industry.

The response rate was $85 \%$. This study reduced the reporting bias and obtained a series of statistical diagrams that showed the development trend of AHP composite materials in aircraft industry. The survey carried out in this project indicates that autoclave curing is taken as the most important composite processing technology in aerospace manufacturing, and approximately $98 \%$ composite components are made by autoclave in some military projects. The contributing factors causing AHP composite materials' deformations in autoclave curing are shown in Figure 2.

The total grade is 9.0 and the statistics data is the average value. The grades of different features in the whole composite parts fabricated in their plants have been analyzed in Figure 3(a). The grades of different tooling materials used in plants are analyzed in Figure 3(b).

Those survey data indicates that the large size, complex surface and anisotropic composite materials have a big proportion in aircraft composites. The composite parts larger than $5 \mathrm{~m}$ get grade value of 4.3. Complex surface parts reach grade value of 4.2. The advanced tooling materials, such as Invar and composite still need further development. But the survey also exhibits that the composite tooling application has a big increase in recent years. Figure 4 shows the grades of problems in the curing of thick composite parts (more than $20 \mathrm{~mm}$ in thickness) and problems in tooling design process. Large temperature gradient and deformations have a very high score nowadays curing technologies, nearly 8.2 scores. This means that conventional thermal heating techniques cannot solve the curing problems of thick composite parts. The relationship of tooling design and deformation of parts still puzzles the engineers in plant. 


\section{Literature Survey}

Since 1980, advanced composite materials have been used in F-18 fighter aircrafts. With the development of technology, composite materials are applied to the whole wings and fuselages of state-of-the-art fighters, accounting for nearly $25 \%$ to $50 \%$ of the whole aircraft weight, Such as F-22 and EF2000 [15]. The characteristics of composites determined that it can only be achieved by the integration of digital design and manufacturing technologies. The design and processing method for aircraft structures of polymer composite materials have been described in numerous books and papers, including those by Schwartz [16] and Ye [17].

Many processing methods have been developed in recent years, as the autoclave curing method has a variety of major advantages, but processing AHP composite laminates still remain as a big challenge in aerospace field. Figure 5 shows a large composite wing panel of Airbus large transporter A400M [18]. The appropriate tooling design methodologies can reduce the tooling-part interaction and increase the accuracy of composite parts. The non-uniform curing is mainly caused by uneven temperature distribution, so the Microwave curing techniques can be considered to solve this problem. Microwave curing technology can accomplish a synchronous inside-out cure in thick-section composite to obtain an even temperature distribution and reduce the deformation of composite components used in the aerospace applications. This technology is investigated in this paper to reduce the in-plane and thick-direction temperature distribution, which can also reduce energy consumption.

\subsection{Tooling of Composite Materials}

The control of part shape and deformation is significant in manufacturing of composite materials. The matching of CTEs of fiber and matrix materials is very difficult to achieve, due to the deformation nature of fiber reinforced composite materials. However, the tooling surface and tooling-part interaction can be designed and calibrated to achieve higher components accuracy and quality. For this reason, tooling design is thought as vital but often is underappreciated silent partner behind every well-designed composite part [19]. 


\subsubsection{Tooling Materials}

Differences in thermal properties between the tooling materials and fiber reinforced composite materials often lead to severe stresses in the composite parts during autoclave processing. These stresses may have a strong influence on the deformation of composite structures [20]. The influence of the tooling materials are discussed in this paper. Metal tooling, like steel and aluminum, have a wide use in aircraft composite parts' processing. Those tooling can fabricate specified geometry which are the same as the composite components. They may also prove to be of lower investment and maintenance cost than other tooling materials [21]. The stable structure of metal tooling in high temperature can guarantee the shape and quality of parts. But high coefficient of thermal expansion (CTE) and excessive weight limit the achievable accuracy and quality of composite materials.

With the continuous development of technologies, invar tooling [22] has drawn researchers' attention, for its low thermal expansion. The practically same CTE value of parts with the composite materials of invar tooling has given less deformation than metal tooling. Wimpenny and Gibbons [23] reported an invar spray technology, aiming at developing a manufacturing route for large aerospace composite forming tooling. They also developed a method of spray invar tooling, other than machining for composite aerospace components. The mechanical properties of the coatings were found to be low, compared to bulk invar [24]. Figure 6 shows an invar tooling manufactured by Lockheed company to process the composite laminate of F-35 aircraft [25]. However, the invar tooling has a very high price and difficult-to-cut characteristics. This makes it difficult to promote in some low cost fields.

Table 1 indicates that the composite tooling has low manufacture costs, weight, CTE and better control of deformation than invar and conventional tooling materials. High Specific heat capacity of composite tooling can uniform the temperature of parts and reduce the curing time. It is most important that composite tooling offers a simplifying tooling design and reduces time of building, which is low in cost, rigid, durable and thermally stable. Many companies such as advanced composites group (ACG) produced autoclave-cure tooling system that offers a thermal cycling capability up to $200^{\circ} \mathrm{C} / 392^{\circ} \mathrm{F}[26]$.

John Wanberg et al [27] indicated that composite tooling is extremely cost effective for moulding exceptional high-quality parts. Zhou [28] studied composite tooling and claimed that it can 
reduce the heat capacity and temperature difference of composite component during curing process and match the CTE between tooling and component by reasonable design. Ao [29] reported that composite tooling can provide high accuracy of radar antenna, e.g., the accuracy of composite antenna can be less than $0.04 \mathrm{~mm}$. Fan and Zhang [17] investigated large size and critical dimensional and geometric accuracy aircraft composite parts, and predicted that more large complex composite structures will be used in military and civil aircrafts, and the corresponding tooling should be fabricated. A composite tooling of $4 \mathrm{~m}$ width, $8 \mathrm{~m}$ length is fabricate by Hexcel Company applied in the future A350 XWB aircraft fuselage panels [30]. The composite parts processed by those tooling achieved good surface quality and accuracy than by metal tooling. On this account, more and more tooling is being built using composite materials, particularly where dimensions or mould stability are critical.

\subsubsection{Calculation of Composite Material Deformation}

Many researchers studied the design of tooling surface to obtain the required tool shapes. GKN aerospace company investigated less expensive composite tooling and concluded that it may provide the optimum solution for the future [31]. Potter et al [32] investigated four flat moulds: aluminum, steel, carbon composite and carbon foam curing unidirectional laminates. As a result, severe residual strains were found in the longitudinal direction for the samples cured on aluminum or steel moulds, whereas the samples cured on carbon-based moulds exhibited almost no strain after cooling-down.

As commonly known, tooling-rework is time consuming and costly. In order to get the dimensional and geometric accuracy of composite components, numerical analysis such as Finite Element Modeling (FEM) has been used to calibrate tooling geometry. Jung et al [33] developed two numerical models to calculate spring-back and compensate tooling geometries for hybrid carbon-glass laminates. Zeng and Raghavan [34] studied the tool-part relationship in autoclave process induced deformation of a large composite structure using a 3D finite element process model. A comparison of predictions using various models for this research suggested that the process induced stress of composite components were caused by constrained deformation of the tool and the part. Simulation programs have also been developed to achieve low deformation and reduce errors caused by unskilled engineers and nonlinear complicated contact treatment $[35,36]$. The in-plane 
and through thickness thermal and chemical stress of composite laminates have been considered to build 3D finite element simulations for calibrate tooling design in post-cure distortions [37-39].

In addition, calculation methods have been studied to predict the deformation of composite material. Hyper [40, 41] was the pioneer to establish geometric formula and calculate the thermal deformations in anisotropic composite material, which is cross-ply composites. Nawab et al [42] calculated the thermal and chemical deformations together, by considering a non-linear geometrical approach to understanding the evolution of shape and hence residual stresses induced during carbon/epoxy laminates fabrication process. The effect of fiber fraction on the chemical and thermal deformations was studied as well.

\subsubsection{The Application of Anisotropic Composite Materials}

The anisotropic fiber reinforced composite parts, for instance the non-symmetric composite materials, have military and commercial applications for Unmanned Aerial Vehicles (UAVs) to stow their wings and control surfaces into very small volumes to permit gun launch or packaging into aircraft mounted aerial drop assemblies [43-45]. A study funded by Sandia National Laboratories (Albuquerque, N.M., U.S.A.) has produced an "adaptive" composite wind blade, which promises to reduce the cost of energy from a $1.5 \mathrm{MW}$ turbine by about $2 \%$. The $9 \mathrm{~m}$ "adaptive" blade's anisotropic laminate design helps the pitch control system maintaining a steadier flow of electrical power under these sudden, transient and localized wind conditions [46]. Moore et al [47] studied the

stability characteristics and thermal response of a bi-stable composite plate with different asymmetric composition. The non-linear finite element method (FEM) was utilized to determine the response of the laminate. Figure 7 shows an aircraft winglet model with the FEM predicted stable configurations without any continuous power source or mechanical conjunctions. They thought that using of this supreme morphing ability can enhance the performance of the aircraft, although it has not been industrialized yet.

Bowen et al [12] investigated the asymmetrical carbon fiber/epoxy composites with bonded piezoelectric actuators. The shape change and morphing of composite materials have been successfully obtained by experiment application. Friswell and Inman [48] reported the use of an asymmetrical laminated composite as an alternative approach to realize a variable sweep unmanned aerial vehicles (UAVs) wing. In order to overcome the aerodynamic loads, two spar wings with an 
asymmetric laminate region close to the root were applied. Many other authors [49-51] studied the asymmetric composite materials at room-temperature and predicted the application of bi-stable laminates in morphing or adaptive aircraft winglet with the experimental approach.

\subsection{Microwave Curing of Polymer Composite Materials}

Thick-section AHP composite materials have unacceptable temperature difference in the thickness direction and this phenomenon can cause non-uniform curing, which contribute a remarkable percentage to composite warpage. Thus, this project proposes microwave curing technologies to optimize the in-plane and thick-direction temperature distribution, which can also reduce production cycle and obtain good quality.

\subsubsection{Comparison of Different Heating Technologies}

For polymer composite materials, there are many processing techniques. Most polymer matrix composite materials need to be heated to have crosslink reaction. The conventional heating method is electrical heating, such as the technologies used in autoclave and thermal curing oven. The main principle is heating the air in the oven, then through thermal heat convection and radiation to heating the composite materials and tooling [52]. Autoclave processing can produce strong, quality composites with higher fiber volume percentage and low void fractions [53, 54]. For this reason, autoclave processing with vacuum is commonly used for manufacturing composite components for the aerospace industry [55]. However, the thermal transfer process can only be controlled indirectly by cure temperature cycle, as thermal convection occurs spontaneously. Autoclave moulding process also requires a high capital cost of energy and processing times for accurate temperature and pressure control [56].

Compared with electrical heating, electron-beam curing is a non-thermal, non-autoclave curing process [57]. It has essential difference with the conventional thermal curing. The electron-beam curing can reduce curing times, improve the composite part quality and performance and reduced overall manufacturing costs. Janke et al [58] thought that composite manufacturing technology has recently achieved a major breakthrough for the composites industry by successfully developing electron-beam. Lopata et al [59] studied the electron-beam-curable epoxy resins for the manufacturing of high-performance composites structures. They developed electron-beam curing 
technology which is possible to reduce the processing time and costs while processing composite materials. Zhang et al [60] studied the mechanism of interaction between AS4 carbon fiber and an epoxy matrix in composites cured by electron beam. The inter-laminar shear strength of an electron-beam-cured composite was improved from 72.1 to 81.1 Mpa. But the electron-beam curing cannot penetrate into composite materials. For thick-section composite materials, the temperature gradient is still unacceptable. At the same time, this technology has a strict requirement to the equipments. Other curing methods, like Ultra Violet (UV) processing technologies are also unable to cure the inter materials and need special resin matrix system to have a reaction with UV [61, 62]. X-rays provide the ability to control dose-rate and to penetrate into metal mold [63], but may result in an extremely long curing time and have implications on safety.

Microwave curing technology has a low heating efficiency, long curing time and good control of temperature. As the problems discussed above, the microwave curing technology can deliver the microwave energy directly to materials through molecular interaction with the electromagnetic field. Because microwaves can penetrate into materials and deposit energy, heat can be generated inside the material, that is so quickly and possible to achieve rapid and uniform heating of thick composite materials. The volumetric heating phenomenon means that air around the materials will not be heated, hence energy efficiency is improved. In addition to volumetric heating, energy transfer at a molecular level can have some additional advantages, such as enhancing the adhesive bonding between two composite parts and increasing boundary strength of fiber and polymer matrix [64].

\subsubsection{Microwave}

Microwaves belong to the portion of the electromagnetic spectrum with wavelengths from $1 \mathrm{~mm}$ to $1 \mathrm{~m}$ with corresponding frequencies between $300 \mathrm{MHz}$ and $300 \mathrm{GHz}$ [65]. It is superposition of alternating electromagnetic and magnetic fields. With the wide range of electromagnetic spectrum, microwaves are used for wireless communication and heating. For microwave heating, microwave processing frequencies is limited to a few ranges: $915 \mathrm{MHz}, 2.45 \mathrm{GHz}, 5.8 \mathrm{GHz}$ and $24.124 \mathrm{GHz}$ [65]. 


\subsubsection{Microwave Curing of Composite Materials}

When using microwave in the manufacturing process of composite materials, the dipole steering polarization phenomenon plays a major role for material heating. In electromagnetic field, the dipoles of the material have an interaction with the electric field, which results in the macroscopic dipole moment. The hysteresis of dipole steering polarization with the alternating electric field, finally lead to power dissipation and heating in composite materials. The power dissipation and absorption of microwave energy can be calculated by equation [66]:

$P=2 \pi f \varepsilon^{\prime \prime} E^{2}$

Where $\mathrm{P}$ is absorption of microwave energy, $\pi$ is the circumference-to-diameter ratio, $\mathrm{f}$ is the frequency of microwave, $\varepsilon^{\prime \prime}$ is the dielectric loss of material, which means the efficiency of transform electromagnetic energy to thermal energy, $\mathrm{E}$ is the electric field intensity. For microwave curing of thick composites, the penetration depth also requires consideration to guarantee the temperature distribution. Different frequencies have different penetration depths. The equation related with microwave penetration depth in materials is [67]:

$\mathrm{D}=\mathrm{c} \times \varepsilon^{\circ} /\left(2 \pi \mathrm{f} \varepsilon^{\prime \prime}\right)$

Where $\mathrm{D}$ is the penetration depth, $\mathrm{c}$ is a constant number, $\varepsilon^{\circ}$ is dielectric constant without electromagnetic. Thus, microwave processing efficiency is affected by the dielectric properties of the composite material itself. The energy absorbed across the laminate also depends on the material and thickness. Compared with the whole fiber/resin-matrix composite materials, carbon fiber reinforced composites have the highest dielectric properties in terms of the conductive properties of carbon fiber.

As mentioned above, different composites system can have different microwave processing results and performance. Lee and Springer [68] investigated microwave curing of both glass fiber reinforced and graphite epoxy matrix composites. The glass fiber reinforced composites may be cured effectively by microwaves regardless of ply orientation and polarization angle. Graphite epoxy composites consisting of multidirectional laminate cannot be cured effectively by microwaves, as the electrical conductivity and electromagnetic reflection of graphite fiber bundles. Fang and Scola [69] concluded that microwave energy can be successfully used to fabricate high-performance PETI-5/IM7 polyimide/ graphite prepreg into PETI-5/IM7 composites with better properties than 
using the conventional thermal cure process. Boey and Yap [70] investigated the effect of using different curing agents in microwave curing of an epoxy system and suggested that the microwave curing was more effective in enhancing the reaction rates during crosslinking. Ku and Siores [71] reported that microwave irradiation did reduce curing shrinkage of the components cast from uncured $33 \%$ by weight or $44 \%$ by volume of fly ash particulate-reinforced vinyl esters. Ismail et al [72] compared microwave energy and conventional curing 5292A bismaleimide resin. They realized that there was no difference in the chemical reactions taking place during the microwave curing and the thermal curing. Zhao et al [72] studied a mathematical model that can be used to optimise microwave heating devices, enabling the configuration to deliver a uniform electric field to process thermosetting of epoxy resin layers of material.

For thick composite laminates, thermal gradients in thick direction always confused the researcher. The study of processing a thick composite laminate found a very low heating rate before gel point which can control the temperature in an allowed range. But the manufacturing time is increased by $27 \%$ [74-76]. Autoclave curing thick-section laminates may cause anisotropy of viscosity and degree of curing. That can harm the composite property and produce micro-cracks [77]. Erik and Tsu [14] studied both microwave curing and thermal curing of thick-section glass/epoxy laminates. They discovered that microwave curing promotes an inside-out cure, dramatically reduced thermal gradients and the overall processing time. They also researched the numerical process simulation of a thick composite laminate processed using conventional and microwave techniques [78]. Wei et al [79] reported microwave curing of thick cross-ply carbon fiber/epoxy composites in a single mode microwave cavities. The 24-ply cross ply graphite fiber/epoxy composite laminates had been processed in a cavity using $2.45 \mathrm{GHz}$ microwave radiation. 72-ply unidirectional and cross ply composites also had been successfully cured. Results of the numerical and experimental work show that microwaves accelerate the curing of thick laminates through accelerated chemical reaction kinetics and direct, efficient coupling of energy throughout the material thickness. Qaddoumi et al [80] reported that microwave energy can provide uniform and fast heating for thick sandwich composites than conventional thermal techniques.

The measurement of thermal gradients in microwave curing of composite materials is different from using the thermal heating technology. The conventional metal-based thermoelectric cannot be used in microwave cavity, because the metal sensor may be self-heated by electromagnetic wave 
induced surface eddy current [81]. Yarlagadda and Cheok [82] studied the temperature-feedback control system of microwave curing, which was able to provide a precise and considered temperature control strategy for the localized hot spots and thermal run-away. They applied an infrared thermometer to measure the surface temperature of the composite materials. Degamber $[83,84]$ developed a low-cost, disposable fiber optic temperature sensor in the microwave oven and embed in the materials. This study demonstrated the successful deployment of two optical fiber sensors inside a microwave oven for monitoring the cure and temperature on line during a curing process. But, those measuring method should destroy the structure of composite parts. Vötsch Hephaistos Microwave Company [85] used the thermal imaging camera system to measure the temperature and obtained a better result.

\subsubsection{Variable Frequency Microwave Curing Technologies}

At present, most widely used microwave curing technologies are fixed-frequency and single model resonant cavity. However, the uneven temperature distribution and hot spots of electromagnetic in fixed-frequency microwave are often problematic [86], which restricted the composite parts performance and quality. Recently, Variable Frequency Microwave (VFM) technologies for material processing have been developed and alleviated the non-uniform heating in microwave processing. The technologies work by sweeping through a band-width of frequencies which are cycled through consecutively and launched into a cavity, resulting in different standing waves with many resonant modes [87].

Zhou [88] studied a VFM curing adhesive bonding in a single mode applicator. Results showed that microwaves reduced the bonding time dramatically and obtained adequate bonding strength. Fang and Scola [69] investigated microwave energy processing carbon fiber reinforced composite materials with a VFM furnace. Antonio and Deam [89] focused on the sweep-rate regime used in VFM and the effect of varying this parameter. They investigated two-dimensional computer model and it was found that a more even temperature distribution could be achieved using a VFM curing method. Ku et al $[90,91]$ have done a lot of work on microwave curing, studied low loss thermoplastic composites materials and presented a VFM technology. Figure 8 shows the microwave energy distribution of fixed frequency microwave and variable frequency microwave [92]. However, 
industrial microwave processing frequencies are limited to a few ranges, as discussed above. This means that VFM facilities cannot be widely used in industrial production.

\subsubsection{Assistive Technologies of Vacuum and Pressure}

As known, microwave energy may induce drying and dehydration of materials, to decrease the toughness and flexural strength of polymer resin. Thus, vacuum technology is necessary to provide the vacuum bag and vacuum environment to retain water in the resin materials. Meanwhile, for aircraft composite components, the fiber volume fraction needs to be maintained at 0.62 to offer a high strength and consolidation. However, without the pressure condition, fiber volume fraction can hardly be over 0.5 in composite curing process.

Boey et al [93] investigated the high-pressure microwave curing process for an epoxy-matrix/ glass-fiber composite materials, and suggested that reduction in void content can be achieved. The usage of a continued vacuum evacuation is also studied. The vacuum bagging system reduces the voids by physically transporting the voids out of the resin and fiber network. An epoxy 0/90 cross-woven E-glass system comprising 12-24 plies composite had been cured in a multi-mode cavity based on a $2.45 \mathrm{GHz}$ magnetron with a wave-guide design. Results showed that industrial application of the microwave curing process still necessitates void reduction, which can be achieved using high-pressure to dissolute the voids. Earlier research work of Boey [94] indicated that the humidity and autoclave pressure affect glass fiber composite materials performance. The pressure during curing increased the Interfacial Shear Strength (ISS) values for all humidity levels.

However, the pressure condition may affect the shape of microwave cavity. The most widely used cavity is rectangle resonant oven. But rectangle shape cannot be applied in pressure environment, due to the stress concentration in the corner. Thostenson and Chou [14] employed a $2.45 \mathrm{GHz}$ multi-mode microwave cavity with 500 liter volume and cylinder shape, as shown in Figure 9(a). But this kind of cavity may cause electromagnetic concentration in the geometric center. Non-uniform temperature may occur. Vötsch Hephaistos Microwave Company [85] developed a hexagon shape microwave oven without pressure as shown in Figure 9(b), and reported that it has an even electromagnetic field compared with cylinder oven. 


\section{Development of AHP Composite Components Curing Technology}

The research and application of ensuring high accuracy of AHP composite laminates are discussed in this paper. The Anisotropic Composite Tooling (ACT) design method has been studied to match the CTE of anisotropic composites, and calibrate tooling surface with nodes displacement of deformed part surface, based on the FEM calculation theory. Microwave curing technology can achieve rapid and uniform heating of AHP composite materials than using other heating methods. For processing better compaction and strength of aircraft composites, Vacuum-Pressure Microwave (VPM) with vacuum and pressure assisted curing technology is established to increase the resin toughness, compaction and to reduce the voids content.

The Anisotropic Composite Tooling (ACT) and Vacuum-Pressure Microwave (VPM) curing technologies are integrated to ensure dimensional and geometric accuracy of part and reduce unacceptable temperature gradient occurred in AHP composite components. Those technical details are discussed in the sub-sections below. Appropriate composite tooling design methodologies can reduce the tooling-part interaction. The non-uniform curing factor, which affects the deformation of AHP composite materials, can be reduced by applying the VPM technology.

The electromagnetic penetrates into the ACT and heats the composite part. ACT controls the composite part deformation and VPM reduces the temperature gradient, the accuracy and quality of AHP composites will be improved effectively. The curing procedure of AHP composite parts by the combination of ACT design and VPM curing technologies is shown in Figure 10. Better performance of AHP composite parts have been obtained in industrial applications. The composite component manufactured by this curing technology can achieve a better accuracy than using traditional processes.

\subsection{Anisotropic Composite Tooling Design}

For the Anisotropic Composite Tooling (ACT) design technology, as shown in Figure 10, the most important process is the design of composite tooling with approximately the same CTE value as the composite parts. That is based on calculating the parts ply direction and material parameters using ESAComp code. This process can ensure that the thermal deformation of composite tooling 
correspondence with composite part in their contact surface and substantially reduce the tooling-part interaction. On the other hand, the original tooling surface needs to be calibrated according to the composite part deformed surface at final dwell temperature. The deformed shapes after curing are in a state of equilibrium in which the total potential energy inside the body is at the minimum. Therefore, the composite deformation can be calculated with non-linear strains-displacement relationship and minimum of total potential energy established by FEM model. Finally, the deformation of anisotropy composite materials is calibrated to the original tooling surface and an approximately the same CTE as the composites parts is achieved in all-directions to ensure that the composite materials cured by ACT can get a high accuracy and quality.

\subsection{Vacuum-Pressure Microwave Curing Technologies}

In Vacuum-Pressure Microwave (VPM) curing process, microwave curing technology is used to heat the composite materials from inside to outside, at the same time, electromagnetic energy is used to increase the resin toughness, and the voids content is reduced by vacuum and pressure environment. The Distributed Temperature Control (DTC) technology has been presented within this framework to further improve the homogeneous of microwave heating. Distributed temperature control technology is developed based on infrared temperature measurement. The temperature measured from the composite materials is fed back to the temperature gradient computation system. The system calculates the fastest temperature variation directions using directional derivative and gradient function on the measurement of several temperature areas. Multiple magnetrons power coupling control module received the computation results, and adjusts the power of multiple magnetrons at corresponding positions according to the fastest temperature variation directions. VPM curing technology cuts down the non-uniform cross-link reaction and thermal stress of composite materials to achieve a high dimensional and geometric accuracy and quality, which can also reduce production cycle and achieve good quality.

\subsection{The Experiment}

To verify the anisotropic composite tooling design and vacuum-pressure microwave curing technologies, a number of unidirectional carbon fiber laminates were used to fabricate a complex composite part and then measured for deformation. The laminates used in present experiment are 
T300/3234 carbon fiber/epoxy unidirectional prepreg (USN150). The specimen in this study is manufactured by hand cutting and lay-up of USN150 prepreg. The temperature cycle for autoclave curing is dwell $100^{\circ} \mathrm{C}(212 \mathrm{~F})$ for 40 minutes and arrive $160^{\circ} \mathrm{C}(320 \mathrm{~F})$ with a temperature ramp rate of $3.2^{\circ} \mathrm{C} / \mathrm{min}(37.8 \mathrm{~F} / \mathrm{min})$ then dwell 1 hour and cooling-down. The thermo-mechanical properties of the prepreg are given in Table 2. In this table, the variable " $T$ " means temperature in curing process. The longitudinal direction is parallel to the fiber direction and the transverse direction is perpendicular to the fiber direction. The composite part is scaled with equal proportion from partial fairing structure for better reflection of advanced high performance composite components in current industrial applications. The $2 \mathrm{~mm}$ thickness part ply is $[45,90,-45,0,90]_{4}$, compared to the $\left[0_{2} / 90_{2}\right]_{2}$ plied asymmetric thin composite part.

The anisotropic composite tooling is $40 \mathrm{~mm}$ long, $20 \mathrm{~mm}$ width and $2.5 \mathrm{~mm}$ thickness, with circular surface and right-angle corner, as shown in Figure 11. The ply direction of tooling is based on the calculate results by ESAComp code to match the CTE of composite part. On the other hand, electromagnetic heating model of finite element method is applied to calculating the deformation of composite part in microwave oven. The composite tooling calibration is achieved through adjusting the tooling surface according to the result of composite part deformation. For convenience of experiment, the tooling is put in a foam model to support the tooling surface.

A microwave oven with infra-red temperature measurement system is shown in Figure 12(a). It includes the infra-red temperature measurement (with two infra-red sensors) and power conditioning systems (with three magnetrons). As the microwaves penetrate into and heat the composite material from inside out, the temperature distribution in thick direction can be the same as in the surface. The microwave oven can run automatically by measuring the surface temperature of composite part and controlling the magnetron power to achieve the set temperature. The on-going research project provides an approach to compute the temperature gradient of two infrared sensors using directional derivative and gradient function. The algorithm of this method is programmed in the temperature controller, which is shown in Figure 12(b). This equipment can receive two signals of infra-red sensors and identify (by calculation) which temperature areas that are uneven, then control the power of the magnetron in respective positions. Microwave curing can offer low curing energy, reduced time and activation energy of the reactions [65]. The temperature cycle for USN150 prepreg is adjusted to satisfy the curing process of microwave by numeral experiments. The dwell temperature 
is $100^{\circ} \mathrm{C}(212 \mathrm{~F})$ for 10 minutes then rapid heating up to $160^{\circ} \mathrm{C}(320 \mathrm{~F})$, dwell 30 minutes and natural cooling to room temperature.

Figure 13 demonstrates the vacuum bagging scheme and materials for composite part curing. For better accuracy of infrared measurement, the breather does not put into the bag. Meanwhile, the ballast load places on the top of the bag to provide the pressure for the composite materials. Two infra-red measurement areas do not put ballast load. The anisotropic composite component is fabricated using the anisotropic composite tooling (see Figure 11). The curvature measurement method and directions are shown in Figure 14. ' $A$ ' and ' $B$ ' are the start points of measurement, ' $C$ ' and ' $\mathrm{D}$ ' are the end points. Measuring the 'A-C' line can get the curvature of circular surface, and measuring the 'B-D' line can obtain the right-angle corner curvature. Through measuring the coordination of composite part and tooling using a coordinate measuring machine, the curvature of composite parts manufactured using vacuum-pressure microwave curing technology are measured in every $5 \mathrm{~mm}$, along the measurement directions.

The comparison of composite part curvature is plotted in Figure 15. This figure shows that the curvature of the composite component manufactured by anisotropic composite tooling, which applied ACT design technology, is significantly reduced.

Due to the smooth of composite part surface, the curve graphs have small fluctuations. The largest curvature occurs at the two edges of composite part along the width direction. In the middle of the composite part, the curvature has a minimum value. The curvature in 'A-C' line is uniformly distributed in both sides and the curvature of composite component manufactured by designed anisotropic composite tooling is much lower than using conventional composite tooling. The largest decreasing of curvature is $5 \mathrm{~mm}$ and lowest is $0.3 \mathrm{~mm}$. The curvature in 'B-D' line do not distribute symmetrically, the curvature near the ' $\mathrm{D}$ ' point is much smaller than the ' $\mathrm{C}$ ' point, as the deformation of asymmetric composite part has been restricted by the right-angle corner. Meanwhile, the measurement points close to the right-angle corner have a fluctuation, as the large deformation of carbon fiber and epoxy materials.

The surface temperature of composite part fabricated in microwave oven has been measured using an infra-red sensor, as shown in Figure 16. Those results demonstrate that the surface temperature optimized by Distributed Temperature Control (DTC) technology can obtain a lower difference with standard temperature cycle than conventional temperature control at heating stage. As the composite part finished curing at $160^{\circ} \mathrm{C}$ temperature, the magnetrons were shut down and let the part natural cooling-down to room temperature. Through analyzing the temperature of two infra-red sensors (such as infra-red sensor 1 and infra-red sensor 2), which measure two different areas of composite part surface, a more even surface temperature distribution can be achieved using DTC technology in microwave oven than using traditional automatic microwave control. More than 
$10^{\circ} \mathrm{C}$ surface temperature fluctuation can be reduced to allow infra-red temperature curve to be near the standard temperature cycle.

Therefore, the composite components using composite tooling, which applied ACT design technology, and manufactured by vacuum-pressure microwave curing method, can increase the accuracy of advanced high performance composite components with features of anisotropic, larger size (in length and thickness), higher accuracy and complex surfaces. Other parts of those technologies have been verified with engineering applications in one of the project collaborating companies.

\section{Conclusions}

The control of dimensional and geometric accuracy of manufactured fiber-reinforced polymer composite components is a major challenge in the aerospace industry, especially for aircraft structure parts of large size (in length and thickness) with complex surfaces. A comprehensive literature survey and industry investigation identified that current tooling use materials which cannot match the thermal expansion of composite parts; and current microwave curing technologies have problems in dealing with large composite materials. The proposed and developed anisotropic composite tooling design method combined with vacuum-pressure microwave curing technology can achieve an impressive increase in the quality of manufactured composite components. Using the method, the thermal expansion of tooling can be predicted and appropriate materials selected so as to match with the expansion of composite parts. The method also provides a tool calibration algorithm to compensate the deformation of composite parts after forming process. The corresponding vacuum-pressure microwave curing technology solves the non-uniform curing problem, and increases the resin toughness and reduces the voids in the volume of the material. However, the technologies for the composite part deformation prediction and the temperature control of microwave curing, need to be further developed before the proposed technologies can be used in industry.

\section{Acknowledgements}

This research work is supported by the 'Outstanding Talents Cultivation Fund' of Nanjing University of Aeronautics and Astronautics (NE2012003) awarded to Professor Yingguang Li. The fund supports international collaboration with 
the Centre for Innovative Product Development and Manufacturing (CiPDM) of the University of Greenwich, headed by Prof James Gao, Medway Chair of Manufacturing Engineering. The authors sincerely appreciate the continuous support provided by our industrial collaborators and all those took part in the industrial investigation.

\section{References}

1. Salonitis K, Pandremenos J, Paralikas J, Chryssolouris G (2010) Multifunctional materials: engineering applications and processing challenges. The International Journal of Advanced Manufacturing Technology 49 (5):803-826

2. Barbero EJ (2010) Introduction to composite materials design. CRC Press Taylor\&Francis Group, USA

3. Golzar M, Poorzeinolabedin M (2010) Prototype fabrication of a composite automobile body based on integrated structure. The International Journal of Advanced Manufacturing Technology 49 (9):1037-1045. DOI:10.1007/s00170-009-2452-6

4. Harris CE, Starnes JH, Shuart MJ (2002) Design and manufacturing of aerospace composite structures, state-of-the-art assessment. Journal of aircraft 39 (4):545-560

5. Red C (2012) Composites in General Aviation 2011-2020. ComposiesWorld. http://www.composites world.com/zones/aerospace-composites/. Accessed 25April 2012

6. Immarigeon J, Holt R, Koul A, Zhao L, Wallace W, Beddoes J (1995) Lightweight materials for aircraft applications. Materials characterization 35 (1):41-67

7. Gibson RF (2010) A review of recent research on mechanics of multifunctional composite materials and structures. Composite structures 92 (12):2793-2810

8. Marsh G (2008) Airbus takes on Boeing with composite A350 XWB. http://www.reinforcedplastics. com/view/1106/airbus-takes-on-boeing-with-composite-a350-xwb/. Accessed 17 November 2012

9. Aerostrategy (2009) Aerospace globalization 2.0. http://www.aerostrategy.com/. Accessed 12 May 2012

10. Roger C, Chad JRO, David Y ( 2011) China's Advancing Aerospace Industry. Rand Corporation, USA

11. Lv J (2009) Composite Material Application in C919 Program. International Forum on Composite Material Applications for Large Commercial Transport Aircraft, Shanghai, China

12. Bowen C, Butler R, Jervis R, Kim H, Salo A (2007) Morphing and shape control using unsymmetrical composites. Journal of intelligent material systems and structures 18 (1):89-98

13. Stewart R (2010) New mould technologies and tooling materials promise advances for composites. Reinforced Plastics 54 (3):30-36

14. Thostenson ET, Chou TW (2001) Microwave and conventional curing of thick-section thermoset composite laminates: Experiment and simulation. Polymer composites 22 (2):197-212

15. Shanyi D (2007) Advanced composite materials and aerospace engineering. Acta Materiae Compositae Sinica, 24 (1): $1-12$

16. Schwartz MM (1997) Composite materials. Volume 2: Processing, fabrication, and applications. New Jersey, United States.

17. Ye L, Lu Y, Su Z, Meng G (2005) Functionalized composite structures for new generation airframes: a review. Composites science and technology 65 (9):1436-1446

18. Yuqing F, Lihua Z (2009) New Development of Extra Large Composite Aircraft Components Application Technology. Advance of Aircraft Manufacture Technology. Acta Aeronautica Et Astronautica Sinica, 30 (3): 534-543 
19. Black S (2011) Tooling for composites evolutionary trajectory. ComposiesWorld. http://www.composites world.com/articles/tooling-for-composites-evolutionary-trajectory. Accessed 12 May 2012

20. Oliveira RD, Lavanchy S, Chatton R, Costantini D, Michaud V, Salathé R, Månson JAE (2008) Experimental investigation of the effect of the mould thermal expansion on the development of internal stresses during carbon fibre composite processing. Composites Part A: Applied Science and Manufacturing 39 (7):1083-1090. DOI:10.1016/j.compositesa. 2008.04.011

21. Vangerko H (1988) Composite tooling for composite components. Composites 19 (6):481-484

22. Kenney E, Fletcher D, Malone R, Wilson B (2004) Invar tooling. Patent

23. Wimpenny DI, Gibbons GJ (2000) Metal spray Invar tooling for composites. Aircraft Engineering and Aerospace Technology: An International Journal 72 (5):430-439

24. Wimpenny DI, Gibbons GJ (2003) Metal spray tooling for composite forming. Journal of Materials Processing Technology 138 (1-3):443-448. DOI:10.1016/s0924-0136(03)00114-6

25. Process Fab Inc (2012) http://www.processfab.com/spv-43.aspx. Accessed 6 August 2012

26. Richardson M (2011) ACG launches new autoclave tooling prepreg system. http://www.aero-mag.com/news/ 20111/723/. Accessed 14 August 2013

27. John W (2010) Composite Materials Handbook \#2. Wolfgang Publications Inc, Stillwater MN

28. Zhou R (2008) Exploiture and application of advanced mould in producing composite, Fiber Reinforced Plastics/ Composites39 (7):209-225

29. Ao LH (2003) Manufacturing technology of high-precision CFRP antenna model. In: The Electronic 10th Institute of Ministry of Information Industry, Chengdu, China, 2003

30. Alirand L (2008) Conclusive preliminary test for hexTOOL. JEC composites (39):108-109

31. Marsh G (2006) GKN Aerospace extends composites boundaries. http://www.aerospace.gknplc.com. Accessed 4 May 2012

32. Potter K, Campbell M, Langer C, Wisnom M (2005) The generation of geometrical deformations due to tool/part interaction in the manufacture of composite components. Composites Part A: Applied Science and Manufacturing 36 (2):301-308

33. Jung WK, Chu WS, Ahn SH, Won MS (2007) Measurement and compensation of spring-back of a hybrid composite beam. Journal of composite materials 41 (7):851-864

34. Zeng X, Raghavan J (2010) Role of tool-part interaction in process-induced warpage of autoclavemanufactured composite structures. Composites Part A: Applied Science and Manufacturing 41 (9):1174-1183

35. Choi J, Jung S, Kim C (2004) Development of an automated design system of a CNG composite vessel using a steel liner manufactured using the DDI process. The International Journal of Advanced Manufacturing Technology 24 (11):781-788

36. Young M, Cartwright B, Paton R, Yu X, Zhang L, Mai YW (2001) Material characterization tests for finite element simulation of the diaphragm forming process. In: 4th International ESAFORM Conference on Material Forming, 2001

37. Ding Y, Chiu W, Liu X (2001) 3D finite element simulation part distortion of curved composite structures. In: 13th International Conference on Composite Materials (ICCM-13). Beijing, China, 2001

38. Liu XL, Sweeting R and Paton R. (2001) An investigation into spring-in of curved composite angels. In: 33rd SAMPE Technical Conference, Seattle, 2001

39. Sweeting R, Liu XL and Paton R (2001) Prediction of process-induced distortion of curved flanged composite laminates. In: 11th International Conference on Composite Structures (ICCS-11), Monash University, Melbourne, 2001 
40. Hyer MW (1981) Some observations on the cured shape of thin unsymmetric laminates. Journal of composite materials 15 (2):175-194

41. Dano ML, Hyer M (2002) Snap-through of unsymmetric fiber-reinforced composite laminates. International journal of solids and structures 39 (1):175-198

42. Nawab Y, Jacquemin F, Casari P, Boyard N, Sobotka V (2012) Evolution of chemical and thermal curvatures in thermoset-laminated composite plates during the fabrication process. Journal of Composite Materials. DOI:10.1177/0021998312440130

43. Cadogan D, Smith T, Uhelsky F, MacKusick M (2004) Morphing inflatable wing development for compact package unmanned aerial vehicles. In: Proceeding of the 45th AIAA/ASME/ASCE/AHS/ASC structures, structural dynamics and materials conference, Palm Springs, California, 2004

44. Dano ML, Jean-St-Laurent M, Fecteau A (2012) Morphing of Bistable Composite Laminates Using Distributed Piezoelectric Actuators. Smart Materials Research 2012:1-8

45. Sofla A, Meguid S, Tan K, Yeo W (2010) Shape morphing of aircraft wing: Status and challenges. Materials \& Design 31 (3):1284-1292

46. Mason K (2004) Anisotropic wind blade design expected to reduce wind-energy costs. http://www. Compositesworld.com/articles/anisotropic-wind-blade-design-expected-to-reduce-wind-energy-costs. Accessed 17 November 2012

47. Moore M, Ziaei-Rad S, Salehi H (2012) Thermal Response and Stability Characteristics of Bistable Composite Laminates by Considering Temperature Dependent Material Properties and Resin Layers. Applied Composite Materials 20 (1):87-106

48. Friswell MI, Inman DJ (2006) Morphing concepts for UAVs. In: Proceedings of the 21st International Unmanned Air Vehicle Systems Conference, Bristol, 2006

49. White R, Hahn T (1992) Process modeling of composite materials: residual stress development during cure. Part II: experimental validation. Journal of Composite Materials 26(16): 2423-2452

50. Sarrazin H, Kim B, Ahn SH, Springer GS (1995) Effects of processing temperature and layup on springback. Journal of composite materials 29 (10):1278-1294

51. Jeronimidis G, Parkyn AT (1988) Residual stresses in carbon fiber-thermoplastic matrix laminates. Journal of Composite Materials 22(5): 401-415

52. Monaghan P, Brogan M, Oosthuizen P (1991) Heat transfer in an autoclave for processing thermoplastic composites. Composites Manufacturing 2 (3-4):233-242

53. Dufour P, Michaud D, Toure Y, Dhurjati PS (2004) A partial differential equation model predictive control strategy: application to autoclave composite processing. Computers \& chemical engineering 28 (4):545-556

54. Park SY, Choi WJ, Choi HS (2010) A comparative study on the properties of GLARE laminates cured by autoclave and autoclave consolidation followed by oven postcuring. The International Journal of Advanced Manufacturing Technology 49 (5):605-613

55. Suong H (2009) Principles of the manufacturing of composite materials. DEStech Publications, Lancaster, USA

56. Lee W, Park JB, LeClair SR, Abrams FL, Garrett PH, Servais RA (1991) Qualitative process automation for autoclave cure of composite parts. Patents

57. Raghavan J, Baillie MR (2000) Electron beam curing of polymer composites. Polymer composites 21 (4):619-629

58. Janke CJ, Dorsey GF, Havens SJ, Lopata VJ (1996) Electron beam curing of epoxy resins by cationic polymerization. Materials and Process Challenges: Aging Systems, Affordability, Alternative Applications 41:196-206 
59. Lopata VJ, Saunders CB, Singh A, Janke CJ, Wrenn GE, Havens SJ (1999) Electron-beam-curable epoxy resins for the manufacture of high-performance composites. Radiation Physics and Chemistry 56 (4):405-415

60. Zhang Z, Liu Y, Huang Y, Liu L, Bao J (2002) The effect of carbon-fiber surface properties on the electron-beam curing of epoxy-resin composites. Composites science and technology 62 (3):331-337

61. Cook WD (1980) Factors affecting the depth of cure of UV-polymerized composites. Journal of Dental Research 59 (5):800-808

62. Ruyter IE, Øysæd H (1982) Conversion in different depths of ultraviolet and visible light activated composite materials. Acta Odontologica 40 (3):179-192

63. Berejka AJ, Cleland M, Galloway R, Gregoire O (2005) X-ray curing of composite materials. Nuclear Instruments and Methods in Physics Research Section B: Beam Interactions with Materials and Atoms 241 (1):847-849

64. Thostenson E, Chou TW (1999) Microwave processing: fundamentals and applications. Composites Part A: Applied Science and Manufacturing 30 (9):1055-1071

65. Meredith RJ (1998) Engineers' handbook of industrial microwave heating. Institution of Electrical Engineers, London

66. Clark DE, Sutton WH (1996) Microwave processing of materials. Annual Review of Materials Science 26 (1):299-331

67. National Research Council (U.S.) Committee (1994) Microwave Processing of Materials, National Academy Press, USA

68. Woo IL, Springer GS (1984) Microwave Curing of Composites. Journal of Composite Materials 18 (4):387-409. DOI:10.1177/002199838401800405

69. Fang X, Scola DA (1999) Investigation of microwave energy to cure carbon fiber reinforced phenylethynylterminated polyimide composites, PETI - 5/IM7. Journal of Polymer Science Part A: Polymer Chemistry 37 (24):4616-4628

70. Boey F, Yap B (2001) Microwave curing of an epoxy-amine system: effect of curing agent on the glass-transition temperature. Polymer testing 20 (8):837-845

71. Ku HS, Siores E (2004) Shrinkage reduction of thermoset matrix particle reinforced composites during curing using microwaves irradiation. Transactions, Hong Kong Institution of Engineers 11 (3):29-34

72. Zhao H, Turner I, Yarlagadda P, Berg K (2001) Numerical modelling and optimisation of a microwave enhanced rapid prototyping. The International Journal of Advanced Manufacturing Technology 17 (12):916-927

73. Zainol I, Day R, Heatley F (2003) Comparison between the thermal and microwave curing of bismaleimide resin. Journal of applied polymer science 90 (10):2764-2774

74. Ciriscioli PR, Wang Q, Springer GS (1992) Autoclave curing-comparisons of model and test results. Journal of composite materials 26 (1):90-102

75. Bogetti TA, Gillespie JW (1991) Two-dimensional cure simulation of thick thermosetting composites. Journal of composite materials 25 (3):239-273

76. Hojjati M, Hoa S (1994) Curing simulation of thick thermosetting composites. Composites Manufacturing 5 (3):159-169

77. Twardowski T, Lin S, Geil P (1993) Curing in thick composite laminates: experiment and simulation. Journal of composite materials 27 (3):216-250

78. Thostenson ET, Chou TW (1998) Microwave-accelerated curing of thick composite laminates. In: 13th Technical Conference of the American Society for Composites, Baltimore, USA, 1998 
79. Wei J, Hawley MC, Jow J, DeLong J (1991) Microwave processing of crossply continuous graphite fiber/epoxy composites. SAMPE Journal 27 (1):33-39

80. Qaddoumi N, Zoughi R, Carriveau G (1996) Microwave detection and depth determination of disbonds in low-permittivity and low-loss thick sandwich composites. Journal of Research in Nondestructive Evaluation 8 (1):51-63

81. Morgan SP (1949) Effect of surface roughness on eddy current losses at microwave frequencies. Journal of Applied Physics 20 (4):352-362

82. Yarlagadda PKDV, Cheok E (1999) Study on the microwave curing of adhesive joints using a temperaturecontrolled feedback system. Journal of Materials Processing Technology 91 (1):128-149

83. Degamber B, Fernando G (2003) Fiber optic sensors for noncontact process monitoring in a microwave environment. Journal of applied polymer science 89 (14):3868-3873

84. Degamber B, Fernando GF (2004) Process monitoring of a thermosetting resin using optical-fiber sensors in a microwave environment. Sensors Journal, IEEE 4 (6):713-721

85. Jeff Sloan (2011) Microwave: An alternative to the autoclave. ComposiesWorld. http://www.composites world.com/articles/microwave-an-alternative-to-the-autoclave. Accessed 20April 2012

86. Liu F, Turner I, Siores E, Groombridge P (1996) Numerical and experimental investigation of the microwave heating of polymer materials inside a ridge waveguide. Journal of microwave power and electromagnetic energy 31 (2):71-81

87. Ku HS, Ball JAR, Siores E, Chan P Complex permittivity of low loss thermoplastic composites using a resonant cavity method. In: 12th International Conference on Composite Materials (ICCM-12), Paris, France, 1999

88. Zhou S, Hawley MC (2003) A study of microwave reaction rate enhancement effect in adhesive bonding of polymers and composites. Composite Structures 61 (4):303-309. DOI:10.1016/s0263-8223(03)00061-8

89. Antonio C, Deam R (2005) Comparison of linear and non-linear sweep rate regimes in variable frequency microwave technique for uniform heating in materials processing. Journal of Materials Processing Technology 169 (2):234-241

90. Ku HS, Siu F, Siores E, Ball JAR (2003) Variable frequency microwave (VFM) processing facilities and application in processing thermoplastic matrix composites. Journal of Materials Processing Technology 139 (1):291-295

91. Ku HS, Siu F, Siores E, Ball JAR, Blicblau AS (2001) Applications of fixed and variable frequency microwave (VFM) facilities in polymeric materials processing and joining. Journal of Materials Processing Technology 113 (1):184-188

92. Bill BY, Geisler, Adams B, Ahmad I (2011) Variable frequency microwave curing. SolidState Technology. http://www.electroiq.com/articles/ap/print/volume-11/issue-4/features/variable-frequency-microwave- curing .html. Accessed 16 August 2012

93. Boey F, Gosling I, Lye S (1992) High-pressure microwave curing process for an epoxy-matrix/glass-fibre composite. Journal of Materials Processing Technology 29 (1):311-319

94. Boey F (1995) Humidity and autoclave pressure effect on the interfacial shear strength of a microwave cured epoxy-glass fibre composite. Polymer testing 14 (5):471-477 


\section{Tooling Design and Microwave Curing Technologies for the Manufacturing of Fiber-reinforced Polymer Composites in Aerospace Applications}

Table 1 Comparison of different tooling materials

\begin{tabular}{lcccc}
\hline Property & Composite & Invar tooling & Steel tooling & Aluminum \\
\hline First tooling costs (RMB) & 600,000 & 700,000 & 300,000 & 250,000 \\
Second tooling costs & 335,000 & 700,000 & 300,000 & 250,000 \\
Thickness $(\mathrm{mm})$ & 6.3 & 15 & 15 & 15 \\
Density $\left(\mathrm{kg} / \mathrm{m}^{3}\right)$ & 1500 & 8100 & 7850 & 2700 \\
Specific heat capacity & 1200 & 460 & 460 & 880 \\
CTE $\left(10^{-6} / \mathrm{K}\right)$ & $1.7 \sim 5.1$ & 2.55 & 12 & 24 \\
Tooling deformation $(\mathrm{mm})$ & 9.4 & 9.8 & 33.3 & 52.5 \\
Parts deformation $(\mathrm{mm})$ & 15 & 15.9 & 47.5 & 62.5 \\
\hline
\end{tabular}

Table 2 Thermo-mechanical properties of composite laminates

\begin{tabular}{lc}
\hline Material & Composite Laminate (USN150) \\
\hline Density $\left(\mathrm{kg} / \mathrm{m}^{3}\right)$ & 1533 \\
Longitudinal elastic modulus (GPa) & 140 \\
Transverse elastic modulus $(\mathrm{GPa})$ & 7.1 \\
Longitudinal thermal expansion $\left(/ 10^{-6}\right)$ & 30 \\
Transverse thermal expansion $\left(/ 10^{-6}\right)$ & 1.5 \\
Thermal conductivity $(\mathrm{W} / \mathrm{m} \mathrm{K})$ & 5.43 \\
Specific heat $(\mathrm{J} / \mathrm{kg} \mathrm{K})$ & $963.5+3.52 * \mathrm{~T}$ \\
\hline
\end{tabular}




\section{Tooling Design and Microwave Curing Technologies}

for the Manufacturing of Fiber-reinforced Polymer Composites in Aerospace Applications

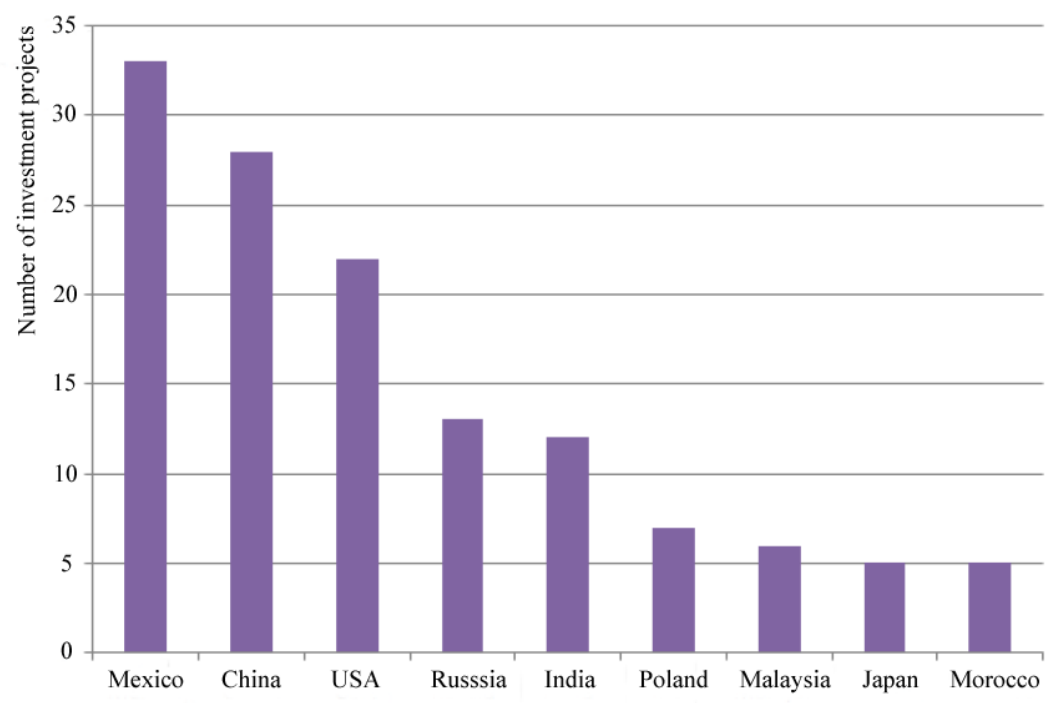

Fig. 1 Major Aerospace Manufacturing Investments from 1990 -2009 [9]

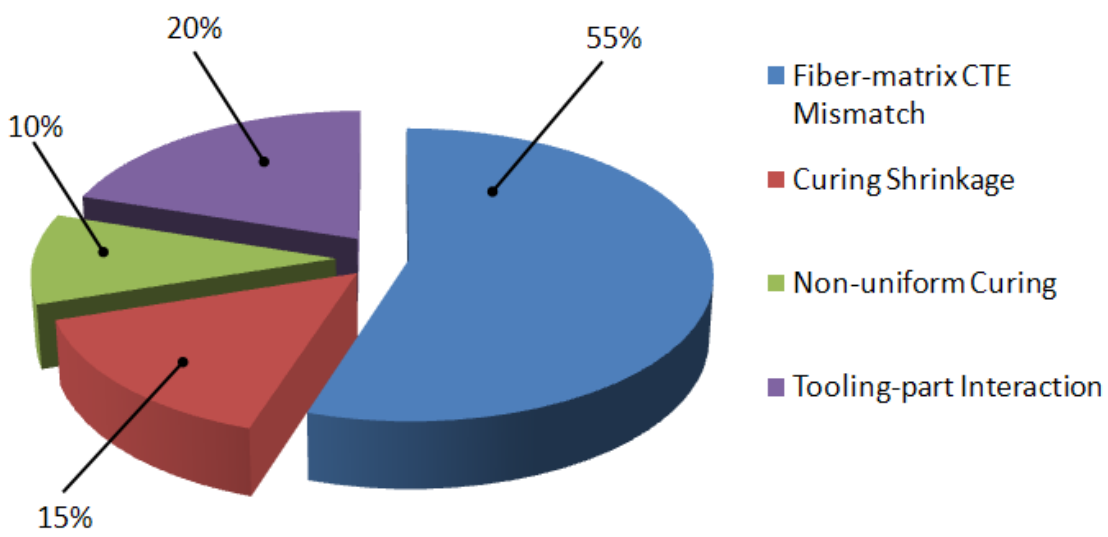

Fig. 2 Questionnaire survey results, sources of deformations for composite products 


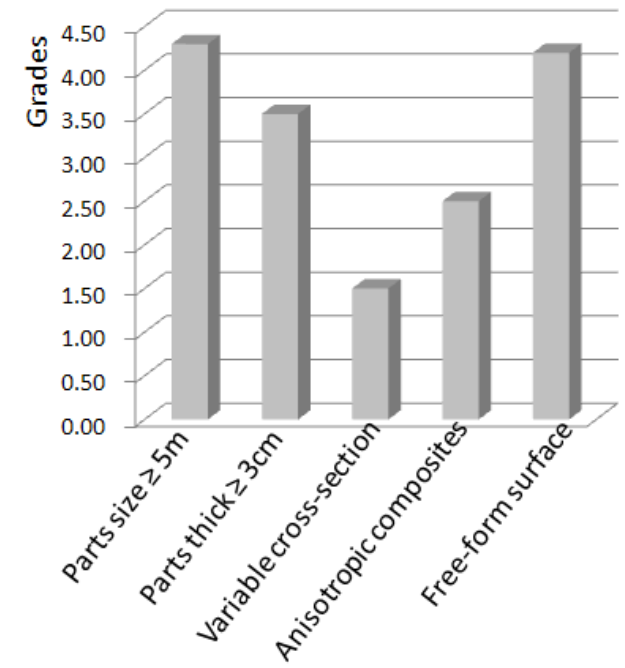

(a)

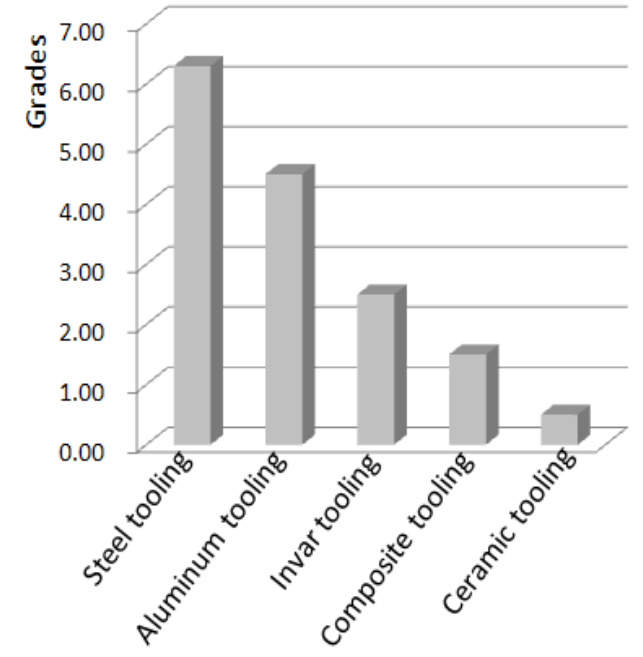

(b)

Fig. 3 Questionnaire survey results, (a) the grade of different features in the whole composite parts, (b) the grade of different tooling materials used in plants

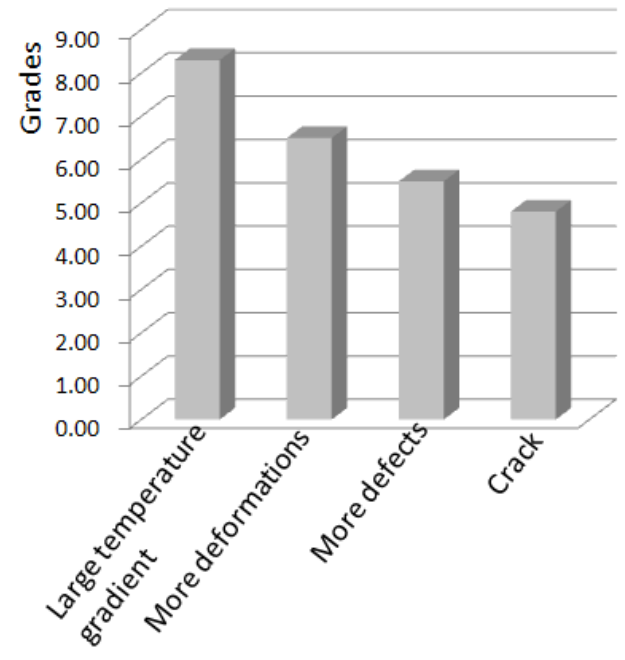

(a)

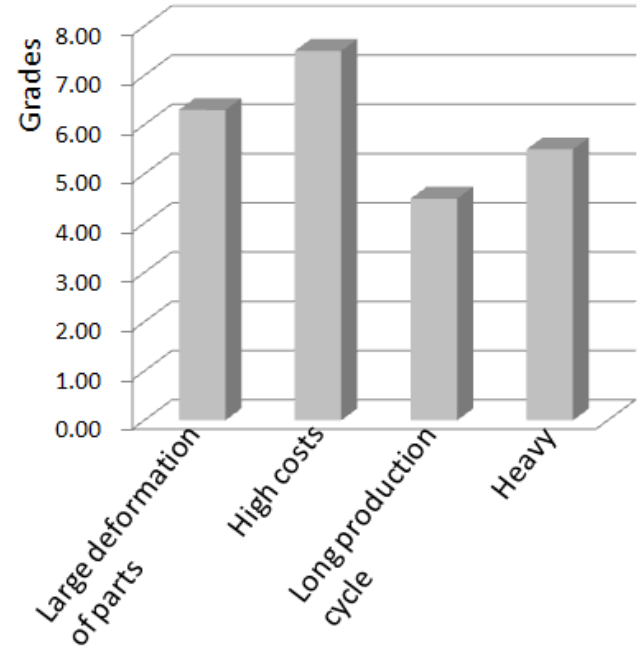

(b)

Fig. 4 Questionnaire survey results, (a) the grade of problems in thick composite parts curing, (b) the grade of problems in tooling design 


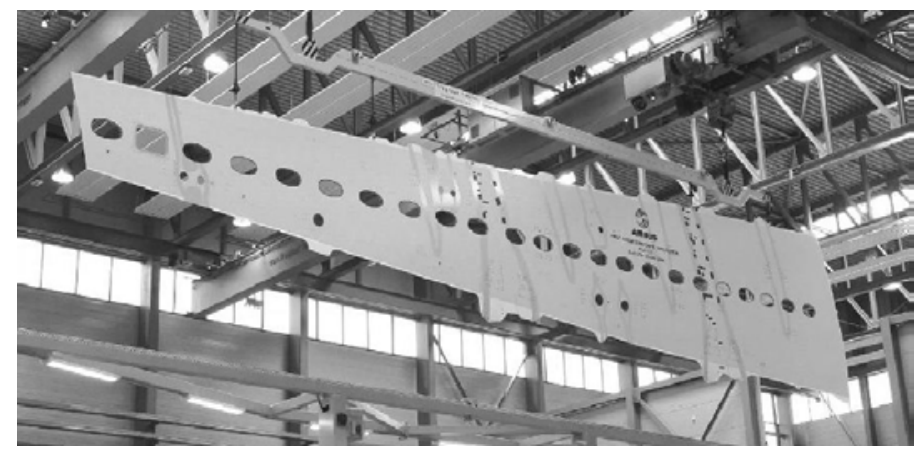

Fig. 5 Composite wing panel of Airbus large transporter A400M [18]

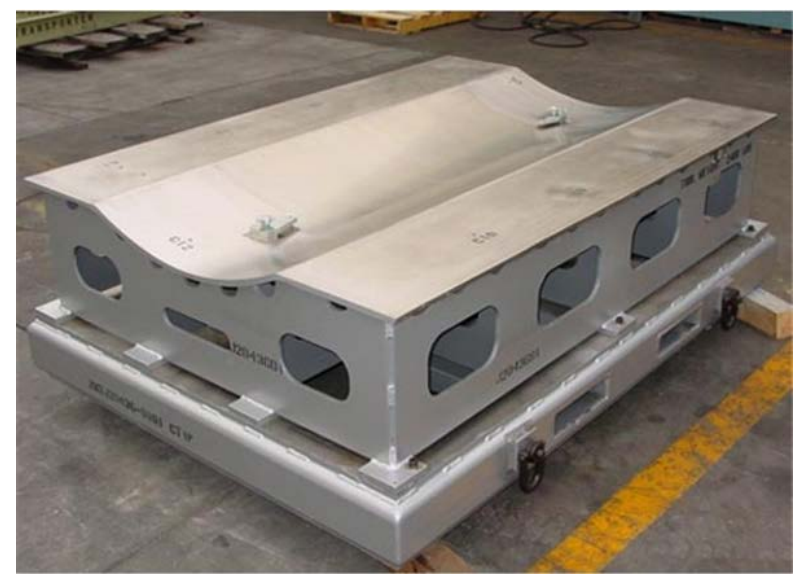

Fig. 6 Lockheed F-35 Invar laminating tooling [25]

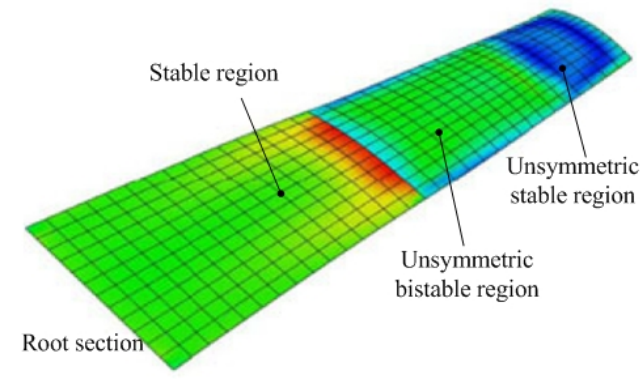

(a)

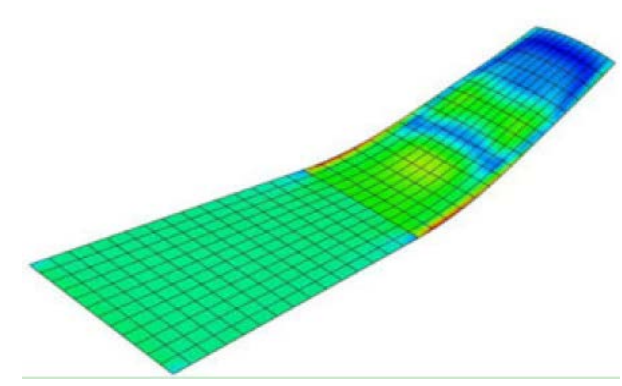

(b)

Fig. 7 Winglet model with the FEA predicted stable configurations. (a) Prediction of first stable shape of composite panel, (b) Prediction of second stable shape of composite panel [47] 

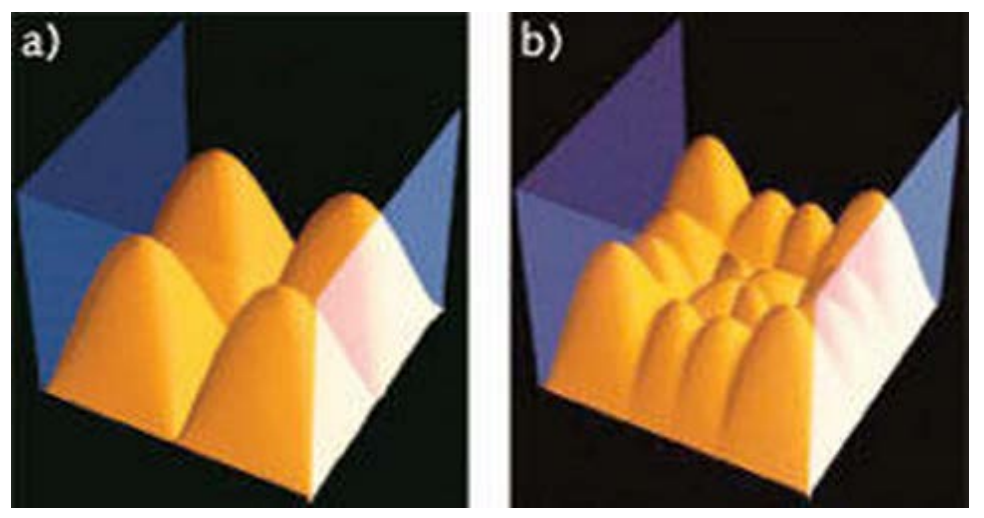

Fig. 8 Schematic representations of microwave energy distribution in cavities for (a) fixed frequency microwave and (b) variable frequency microwave [92]

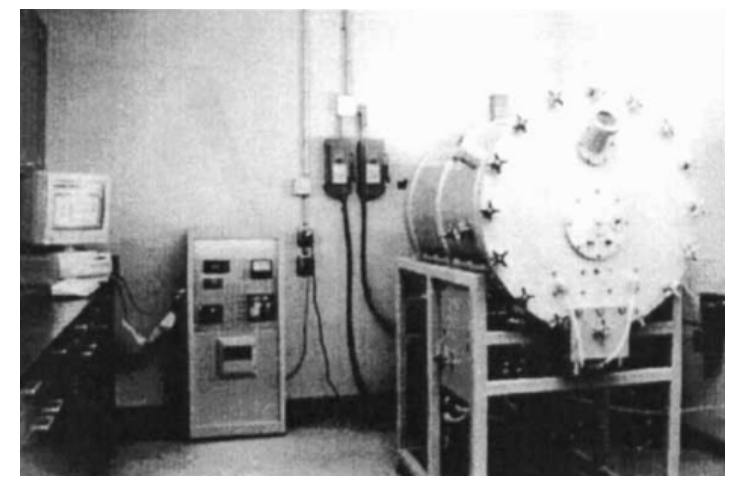

(a)

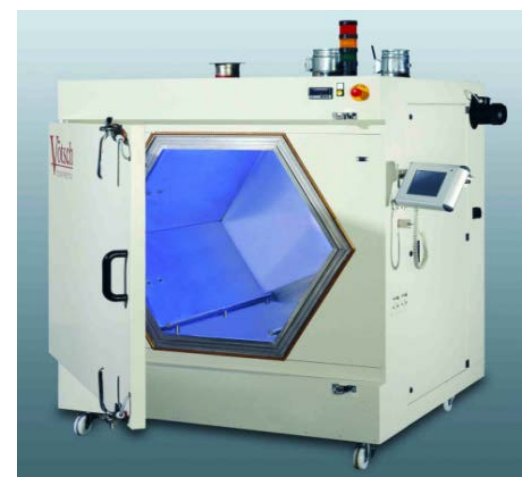

(b)

Fig. 9 2.45GHz multi-mode microwave cavity, (a) pressure assisted microwave oven [14], (b) Vötsch Hephaistos Microwave oven [85] 


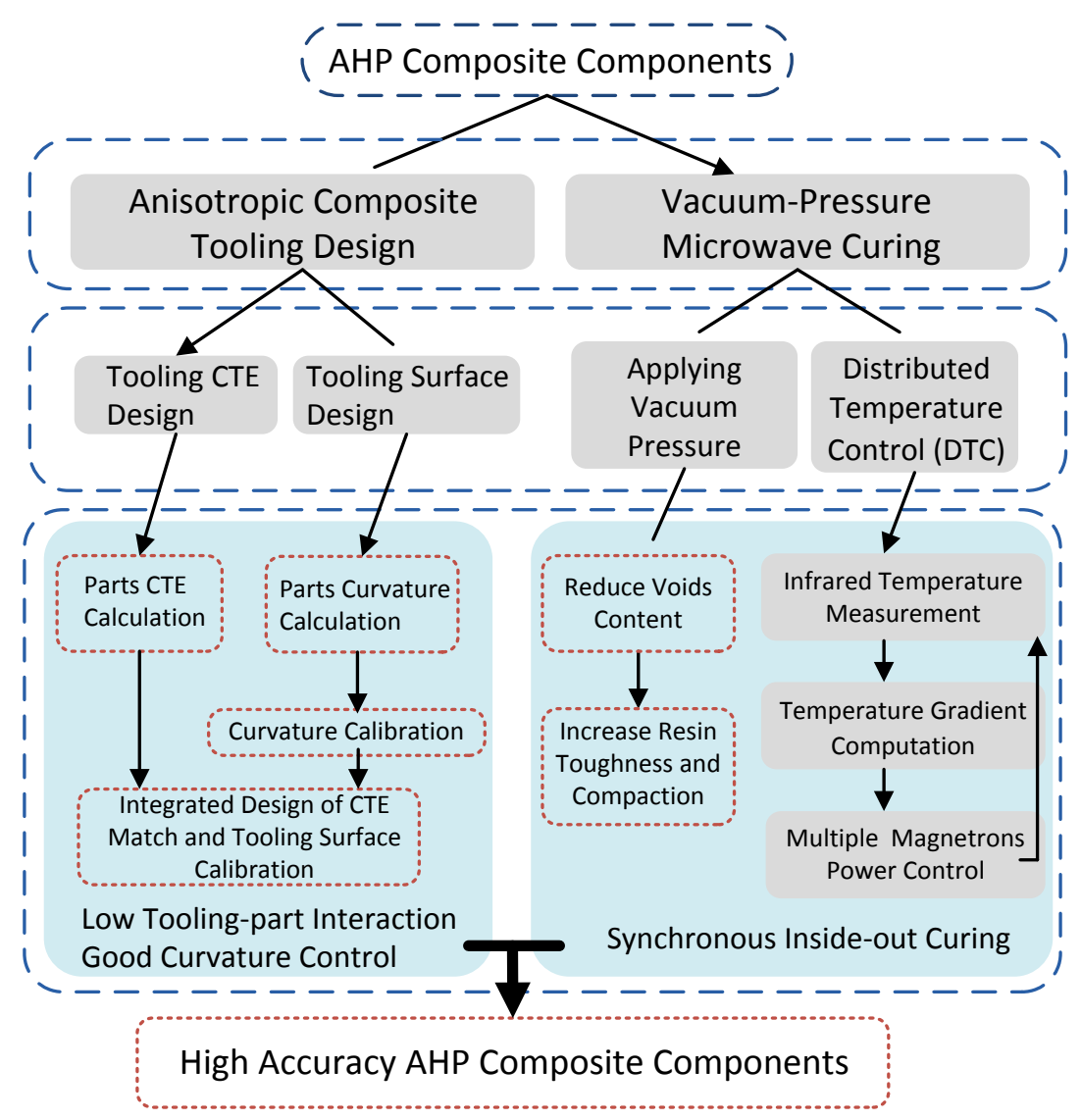

Fig. 10 AHP composite parts curing procedure of combining ACT design and VPM curing technologies

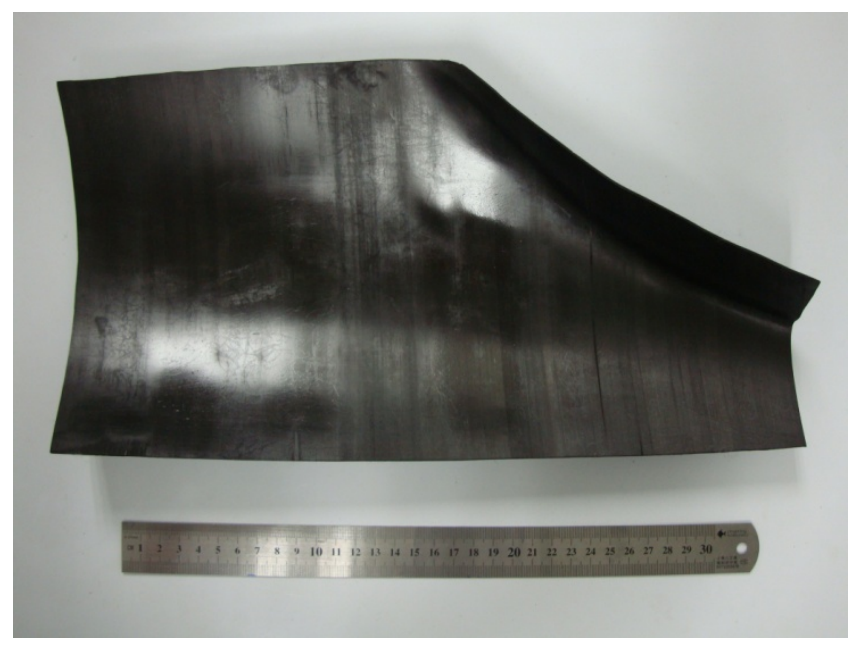

Fig. 11 An anisotropic composite tooling by ACT design 


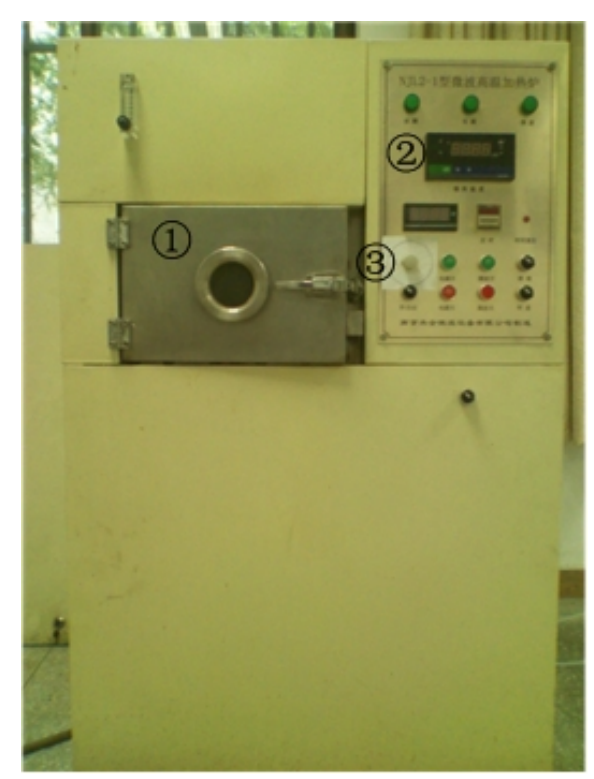

(a)

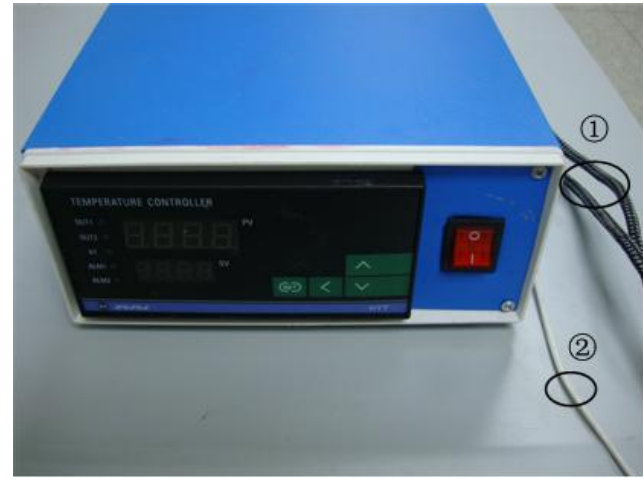

(b)

Fig. 12 (a) A microwave oven with infrared temperature measurement system, (1) Oven door, (2) Infrared temperature measurement system (with two infrared sensors), (3)Power conditioning system (with three magnetrons); (b) Temperature feedback and magnetrons power control system, (1)Magnetrons power control, (2) Temperature feedback sensor

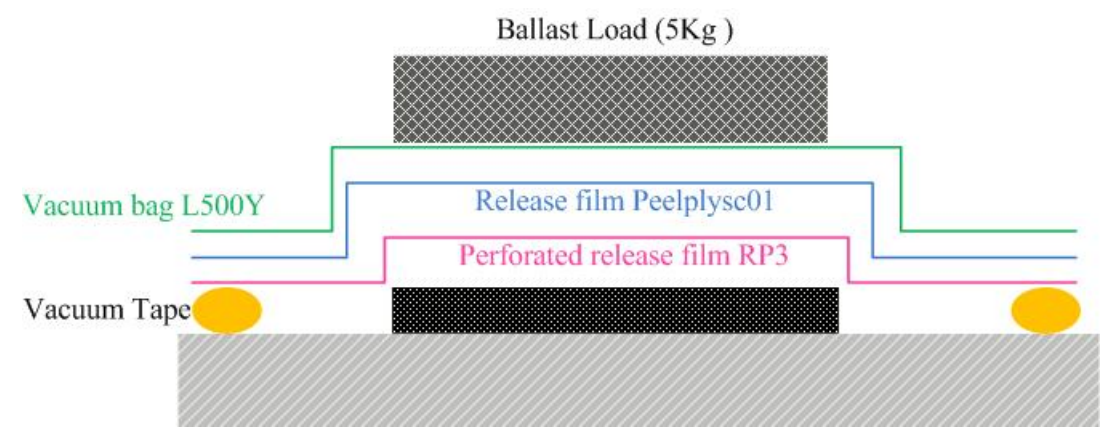

Fig. 13 Bagging scheme for composite part cure 


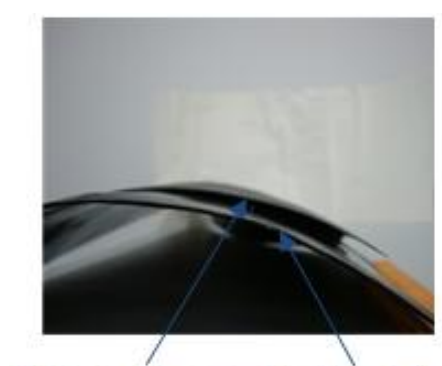

Composite part Tooling

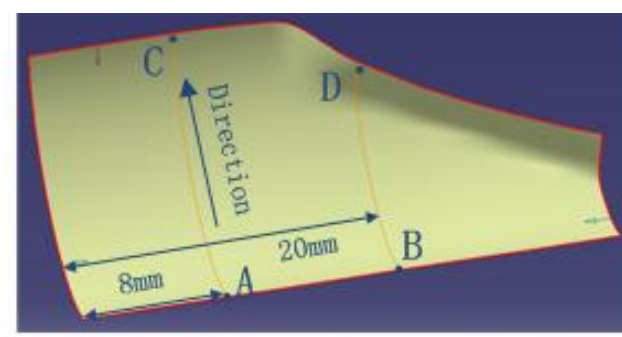

$\mathrm{CAD}$ mode1 and measurement directions

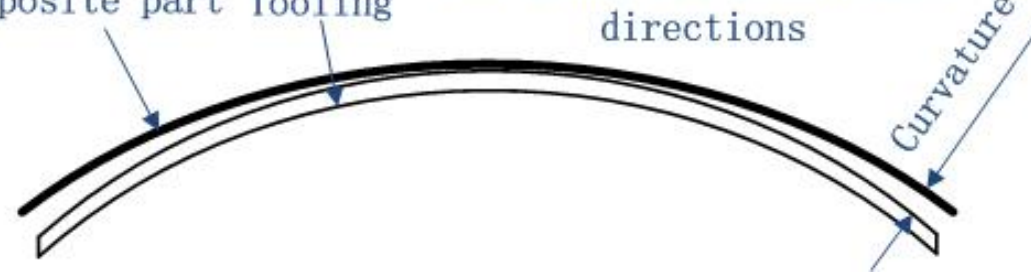

Fig. 14 Curvature measurement and CAD model of composite part

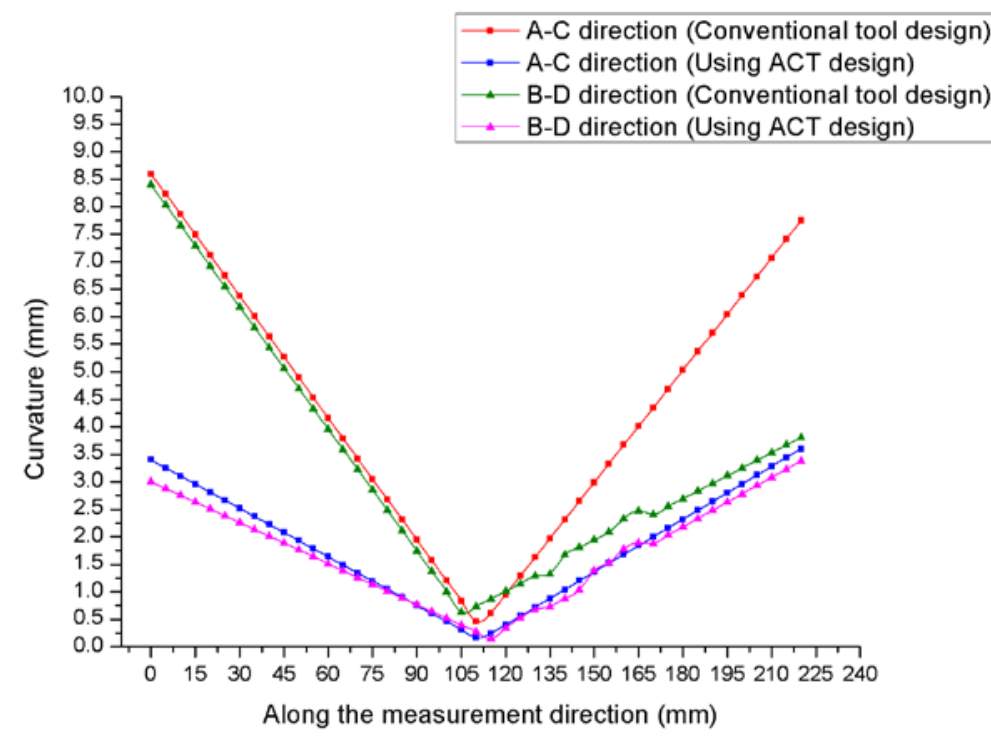

Fig. 15 The comparison of composite part curvature 


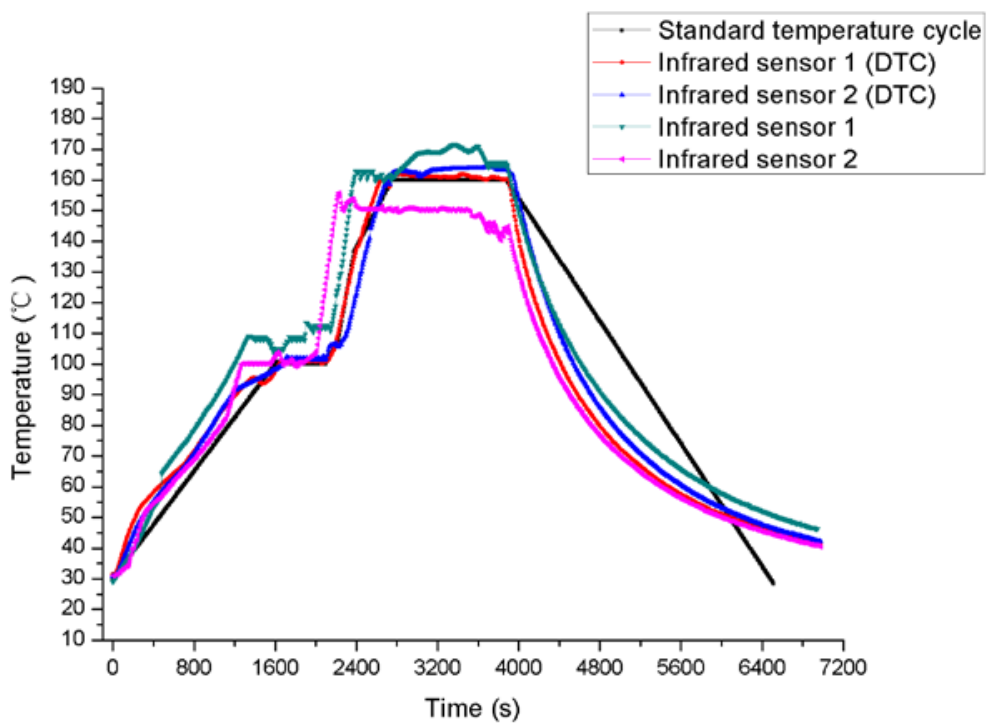

Fig. 16 The surface temperature of composite part measured by infrared sensor 